\title{
Impaired Function of Regulatory T Cells in Type 2 Diabetes Mellitus
}

\author{
Rona Kartika ${ }^{1}$, Heri Wibowo ${ }^{2}$ \\ ${ }^{1}$ Master Program in Biomedical Science, Faculty of Medicine, Universitas Indonesia, Jakarta, Indonesia \\ ${ }^{2}$ Department of Parasitology, Faculty of Medicine, Universitas Indonesia, Jakarta, Indonesia
}

Pathogenesis of type 2 Diabetes Mellitus (DM) is often associated with chronic low-grade inflammation. This kind of inflammation is characterized by an increased level of pro-inflammatory cytokines such as tumor necrosis factor $\alpha$ (TNF- $\alpha$ ), interleukin (IL)- 6 and IL-1 $\beta$. From an immunological point of view, an inflammatory response is always followed by an antiinflammatory response as negative feedback to avoid excessive tissue damages. Regulatory $T$ cells are a subset of cluster of differentiation (CD) $4^{+} T$ cells that have the function to maintain peripheral tolerance and suppress immune response. This review would discuss the impaired function of regulatory T cells in type 2 DM. DM is a group of metabolic diseases characterized by hyperglycemia due to a defect of insulin secretion or a combination of insulin resistance and relative insulin deficiency. Chronic low-grade inflammation has been known as a key factor in the development of insulin resistance. Regulatory T cells (Treg cells) action through contact and non-contact inhibition could suppress inflammatory response in innate and adaptive immune systems. In type $2 \mathrm{DM}$, the proportion and function of $\mathrm{CD} 4^{+} \mathrm{CD} 25^{+} \mathrm{Foxp} 3^{+}$and $\mathrm{CD} 4^{+} \mathrm{CD} 25^{+}$ regulatory $T$ cell decreases due to the reduced number of Treg cells and the Treg cells depletion contributes to metabolic conditions such as insulin resistance. Moreover, Treg cells are more susceptible to apoptosis, the ability of Treg cells to produce anti-inflammatory cytokines such as transforming growth factor $\beta$ (TGF- $\beta$ ) and IL-10 decreases, and there is an imbalance between the proportion of Th1/Th17 cells and Treg cells. This inadequate anti-inflammatory response gives rise to the chronic low-grade inflammatory condition in type $2 \mathrm{DM}$.

Keywords: type 2 diabetes mellitus, inflammation, regulatory T cell

\section{Introduction}

Every year, the prevalence of diabetes mellitus (DM) keeps increasing. Based on International Diabetes Federation, in 2017, this disease affected 415 million people worldwide and it is estimated that the prevalence will increase to
642 million in 2045. ${ }^{1}$ Based on the data from Indonesian Basic Health Research (Riset Kesehatan Dasar/Riskesdas) in 2013, the number of DM patients were $6.9 \%$ for people over 15 years old, and $90 \%$ of them were type 2 DM. $^{2}$ The fatality rate of this disease and its complication was on the third after stroke and acute myocardial infarction. ${ }^{3}$

Date of submission: February 2, 2019

Last Revised: April 18, 2019

Accepted for publication: May 9, 2019

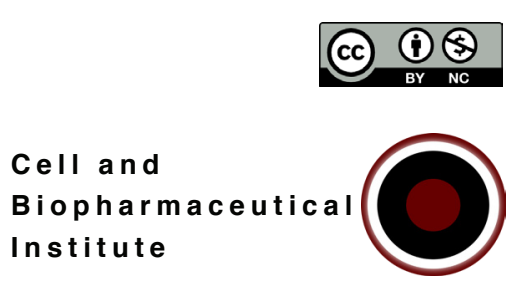

Corresponding Author:

Heri Wibowo

Department of Parasitology, Faculty of Medicine

Universitas Indonesia

Jl. Salemba Raya No.5, Jakarta, Indonesia

E-mail: bowoheri04@gmail.com

Cell and

Institute 
DM is characterized by a group of metabolic diseases, including hyperglycemia due to the defect of insulin secretion or the combination of insulin resistance and relative insulin deficiency. ${ }^{4}$ Insulin resistance is a condition characterized by insulin-sensitive tissues, including skeletal muscle, adipose, and liver tissues are no longer sensitive to insulin. $^{5}$

Inflammation is often correlated with pathomechanism of type 2 DM, such as glucotoxicity, lipotoxicity, oxidative stress, and endoplasmic reticulum stress. ${ }^{6}$ Those mechanisms are the result of various stimuli, including physical inactivity, smoking, sedentary lifestyle, obesity, genetic and environmental factor. Those stimuli could activate C Jun N-terminal kinase (JNK) pathway and inhibitory kappa B kinases (IKKB) pathways that eventually trigger the activation of immune system. ${ }^{7}$ In addition, those stimuli could increase the level of systemic inflammatory mediators secreted by other tissues. These persistent and systematic changes would induce chronic low-grade inflammation. Other studies showed that this inflammation could be a leading factor to insulin resistance, $\beta$ pancreatic cells dysfunction, and eventually type $2 \mathrm{DM}^{8}{ }^{8}$

From immunology's point of view, chronic lowgrade inflammation in type $2 \mathrm{DM}$ is interesting. Every inflammatory stimulus would always be followed by an anti-inflammatory response as negative feedback. ${ }^{9}$ The goal of this feedback mechanism is attenuating immune response after antigen diminished and preventing tissue injury due to overexpression of immune response. On the other hands, there are some hypotheses indicate that the chronic lowgrade inflammation is not strong enough to elicit antiinflammatory activity. ${ }^{8}$

Many studies showed the relationship between type $2 \mathrm{DM}$ and the level of the pro-inflammatory mediators such as tumor necrosis factor $\alpha$ (TNF- $\alpha$ ), interleukin (IL)6 , and IL-1 $\beta .{ }^{10}$ However, the relationship between the antiinflammatory response and their mechanisms contributing to this disease was less explored.

Regulatory $\mathrm{T}$ cells (Treg cells) are cluster of differentiation $(\mathrm{CD}) 4^{+} \mathrm{T}$ cell subset that has the function to maintain peripheral tolerance and suppress adaptive immune responses by secreting anti-inflammatory cytokines, such as transforming growth factor $\beta$ (TGF- $\beta$ ), IL-10 and IL-35. ${ }^{11}$ Previous studies demonstrated that $\mathrm{CD} 4^{+} \mathrm{CD} 25^{+}$Treg and $\mathrm{CD}^{+}{ }^{+} \mathrm{CD} 25^{+} \mathrm{Foxp}^{+}{ }^{+}$Treg cells elicited immune tolerance to self-antigen via contact and non-contact inhibition. ${ }^{11}$ It was believed that the imbalance between inflammatory and anti-inflammatory response was the key factor in the development of type 2 DM. $^{12}$ Therefore, in this paper, we would discuss the anti-inflammatory role of regulatory $\mathrm{T}$ cells in type $2 \mathrm{DM}$.

\section{Diabetes Mellitus}

DM is a group of metabolic diseases characterized by hyperglycemia resulting from the defect of insulin secretion or the combination of insulin resistance and relative insulin deficiency., ${ }^{4,13}$ Based on American Diabetes Association, DM is divided into 4 categories, which are type $1 \mathrm{DM}$ caused by autoimmune $\beta$ cell destruction, type $2 \mathrm{DM}$ caused by a progressive loss of insulin secretion and insulin resistance, and gestational DM diagnosed in the last term of pregnancy, and other specific types of diabetes due to other causes. ${ }^{13,14}$

\section{The Role of Inflammation in Insulin Resistance}

\section{Insulin Functions}

Insulin is a pleiotropic peptide hormone that has various functions, such as transporting nutrients into the cells, regulating genes expression, influencing enzymatic activities, and regulating energy balance via its action in the arcuate nucleus. ${ }^{15}$ Nonetheless, the main function of insulin is inducing intra-cellular glucose transport in insulinsensitive tissues. ${ }^{16}$

\section{Insulin Signalling Pathway}

Insulin signaling is a complex signaling cascade from the insulin receptor, involving 2 major pathways. ${ }^{17}$ The first pathway is phosphatidylinositol-3-kinase (PI3K) AKT which responsible for glucose uptake and suppression of gluconeogenesis. The second pathway is Ras mitogenactivated protein kinase (MAPK) which mediates gene expression and regulates cell differentiation and growth. ${ }^{17}$ The common intermediate of both pathways is insulin receptor substrate (IRS). ${ }^{17}$ Activation of insulin receptor leads to tyrosine phosphorylation of IRS, thus initiating signal transduction.

In the skeletal muscle, insulin induces glucose uptake by stimulating glucose transporter type 4 (GLUT4) translocation into the membrane. Disruption of this insulin signaling leads to the reduction of glucose uptake. ${ }^{15,16} \mathrm{In}$ the liver, insulin inhibits the expression of gluconeogenic enzymes, hence disruption of this signalling would induce the production of hepatic glucose. In adipose tissue, insulin decreases lipase-sensitive hormones activities in order to 
inhibit free fatty acid (FFA) moving out from adipocytes. ${ }^{16}$ The increased FFA level in circulation would induce the reduction of insulin sensitivity in skeletal muscles due to the increasing of intermediate lipids, such as fatty acyl Co-a and ceramides. These intermediate lipids would activate serine/ threonine kinase and protein kinase $\mathrm{C}-\theta$ (PKC- $\theta$ ) leading to the inhibition of insulin signal cascade..$^{15,16}$

\section{Pathogenesis of Insulin Resistance}

Insulin resistance plays a pivotal role in etiology and pathogenesis of type 2 DM. The capability of IRS, particularly IRS1 to regenerate signal is diminished if serine

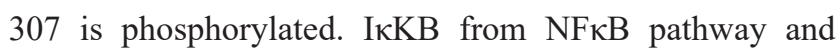
JNK1 from JNK/AP-1 pathway are the most common serine kinases that phosphorylate serine $307 .{ }^{17}$ Activation of those pathways lead to insulin resistance.

The development of insulin resistance is associated with chronic low-grade inflammatory response induced by pro-inflammatory cytokines such as IL-1 $\beta$, IL-6, TNF- $\alpha$, chemokines and adipokines. ${ }^{15}$ In pancreatic $\beta$ cells, chronic exposure of pro-inflammatory mediators also stimulates a cascade of signal protein that inhibits the activation of insulin receptor. ${ }^{15}$

The most abundant pro-inflammatory cytokines involved in $\mathrm{NF} \kappa \mathrm{B}$ and JNK/AP-1 pathways are TNF- $\alpha$, IL-1 $\beta$ and IL-6. ${ }^{10,15,17}$ TNF- $\alpha$ is pro-inflammatory cytokines secreted by monocytes and macrophages. This cytokine has various biological effects, such as lipid metabolism, blood coagulation, and endothelial function. ${ }^{15}$ TNF $\alpha$ binds to cytokine receptor which further induces the activation of transcriptional pathway including NF $\mathrm{B}$ and JNK/AP1. After $\mathrm{NF \kappa B}$ and JNK/AP-1 activated, these pathways would phosphorylate serine 307 on IRS1 that lead to insulin resistance. $^{17}$

IL-1 $\beta$ is a major proinflammatory cytokine that has a crucial role to regulate the expression of other cytokines, chemokines, and adipokines through the involvement of various transcriptional mediated pathways. ${ }^{15}$ This cytokine binds to IL-1 receptor type 1 (IL-1R1) and reduces the expression of IRS-1. Moreover, in $\beta$ cells of pancreatic islet, it impairs insulin secretion. ${ }^{15}$

Beside those mechanisms above, pro-inflammatory cytokines, FFA and oxidative stress could activate expression of Nos2, a gene that encodes inducible nitric oxide synthase (iNOS). In the insulin signaling pathway, nitric oxide (NO) has the ability to reduce AKT activity via s-nitrosylation of cysteine residue. Moreover, increased level of NO could cause degradation of IRS1 in cultured skeletal muscle cells. ${ }^{18}$ Therefore, increased iNOS activity plays an important role in insulin action in skeletal muscle and $\beta$ cells functions. ${ }^{17,18}$

In obesity, the expansion of adipose tissue leads to adipocyte hypertrophy and reduce oxygen supply to adipocytes that cause hypoxia. Hypoxia of adipose tissue could activate the inflammatory response by producing proinflammatory mediators such as TNF- $\alpha$, IL-6, and matrix metalloproteinase (MMP). ${ }^{18}$ These pro-inflammatory mediators would attract macrophages infiltration to the extracellular matrix. Macrophages could digest and store lipid as atherosclerotic foam cell that also produces TNF- $\alpha$ that eventually exaggerate the inflammatory condition. Moreover, in adipose tissue, macrophages could express a large amount of NOS2 and IL-6 that have a contribution to insulin resistance. ${ }^{18}$

\section{Treg Cell}

Treg cells are $\mathrm{CD}^{+} \mathrm{T}$ cells that express CD25, an $\alpha$-chain IL-2 receptor, and Foxp3, a transcriptional factor for Treg cells differentiation. ${ }^{19}$ Therefore, Treg cell could be recognized by the expression of $\mathrm{CD}^{+}, \mathrm{CD} 25^{+}$, and $\mathrm{Foxp}^{+}$, although not all of the Treg cells express those receptors and transcriptional factor. Most of Treg cells maturation take place in thymus and they are called natural Treg cells (nTreg), meanwhile, the others develop in peripheral lymphoid organs due to antigen recognition, so they are known as inducible Treg (iTreg). ${ }^{20}$

Treg cells have the various functions on controlling immune response in the body, such as preventing autoimmune disease, inducing immunologic tolerance to self-antigens, inducing immune tolerance to fetus in pregnant women, repressing immune pathologic response that induced by pathogen, as a feedback mechanism from immune response, protecting normal flora in gut system, and preventing overactivity of effector $\mathrm{T}$ cells that lead to diseases. $^{20}$

The existence and function of Treg cells depend on IL$2 .{ }^{20} \mathrm{IL}-2$ is an important key for Foxp3 transcription in the thymus as well as peripheral lymphoid organs. IL-2 promotes the expression of Foxp3 by binding transcriptional factor signal transducer and activator of transcription (STAT)-5 to Foxp3 promoter and Treg-specific demethylated region (TSDR), an enhancer for Foxp3 gene (Figure 1). ${ }^{20}$ IL-2, accompanied by TGF- $\beta$ could induce the polarization of naïve $\mathrm{CD}^{+}{ }^{+} \mathrm{T}$ cell to Foxp3 ${ }^{+}$iTreg cell. ${ }^{21}$ 
The cytotoxic T-lymphocyte-associated antigen 4 (CTLA-4) is an inhibitory receptor on the surface of Treg cells. ${ }^{21}$ The function of this receptor is terminating effector $\mathrm{T}$ cell activity and mediating the suppressive action of Treg cells. In the Treg cell, the expression of CTLA-4 is regulated by Foxp3. CTLA-4 acts by blocking and removing B7 (CD80 and 86) molecules from antigen presenting cells (APC) surface, thereby reducing co-stimulation and preventing the activation of T cells. ${ }^{21}$ It is still debatable how T cells choose CD28 or CTLA-4. However, there is a fact that CTLA-4 affinity to B7 molecule is higher than CD28. When APC is presenting self-antigen, it expresses the low level of B7 molecules, so these molecules eventually bind to CTLA-4 and they would inhibit the immune response. On the contrary, in pathogenic infection, APC would express the high level of $\mathrm{B} 7$ molecules, therefore $\mathrm{CD} 28$ would bind to $\mathrm{B} 7$ molecules, and induce immune response. ${ }^{21}$

\section{Suppressive Actions of Regulatory T Cells}

Treg cells could suppress immune response through 3 mechanisms, which are non-contact inhibition, contact inhibition, and competition for IL-2 between effector T cells and Treg cells. ${ }^{22,23}$
During non-contact inhibition, both suppressive cytokines TGF- $\beta$ and IL-10 are the most important players (Figure 2 ). ${ }^{23}$ TGF- $\beta$ is not only produced by Treg cells but also produced by other cell types, like APCs after activated by Treg cells. ${ }^{23}$ TGF- $\beta$ as membrane-bound cytokine could induce effector $\mathrm{T}$ cells to respond Tregs action, increase the expression of Foxp3 in Treg cell, and other suppressive actions that have a contribution to $\mathrm{T}$ cell differentiation to Treg cell. ${ }^{24}$ IL-10 is a potent anti-inflammatory cytokine that has the ability to inhibit pro-inflammatory cytokines production, such as interferon (IFN)- $\gamma$, TNF- $\alpha$, IL-1 $\beta$ and IL-6. IL-10 could also prevent maturation of dendritic cell (DC) via inhibiting IL-12 expression. ${ }^{25}$ Moreover, IL-10 could suppress the expression of major histocompatibility complex (MHC) class II and co-stimulatory molecules B7 in $\mathrm{APCs} .{ }^{25,26}$

Suppressive activity of Treg cells could be carried out by the mechanism of contact inhibition. It has been proven that Treg cells are unable to suppress the proliferation of effector $\mathrm{T}$ cell when both are separated by the semipermeable membrane.${ }^{27}$ During this action, Treg cells could eliminate effector $\mathrm{T}$ cells by secreting granzyme or perforin, and sending negative signal to disrupt the metabolism of effector $\mathrm{T}$ cells through increased intracellular cyclic

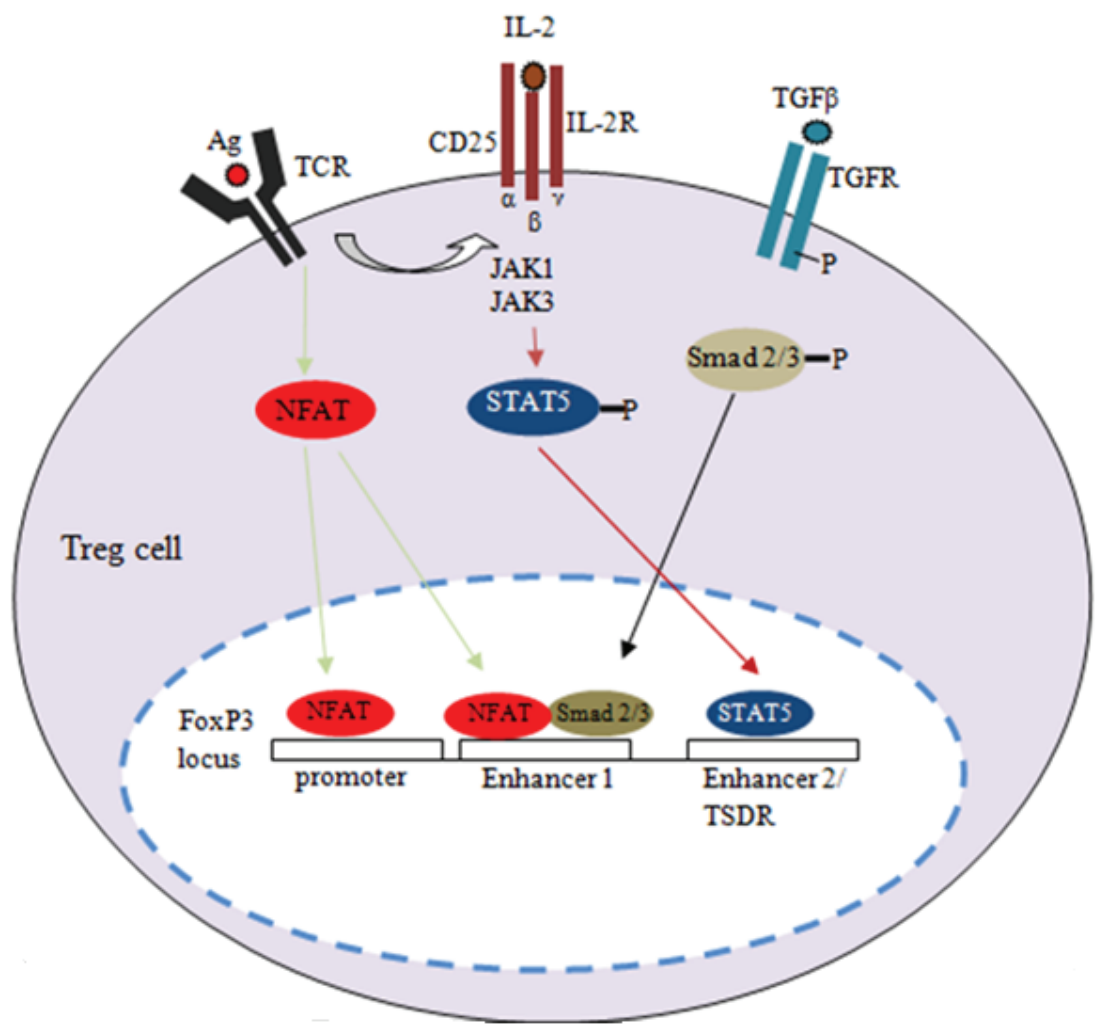

Figure 1. Molecular mechanism for Foxp3 gene transcription. 


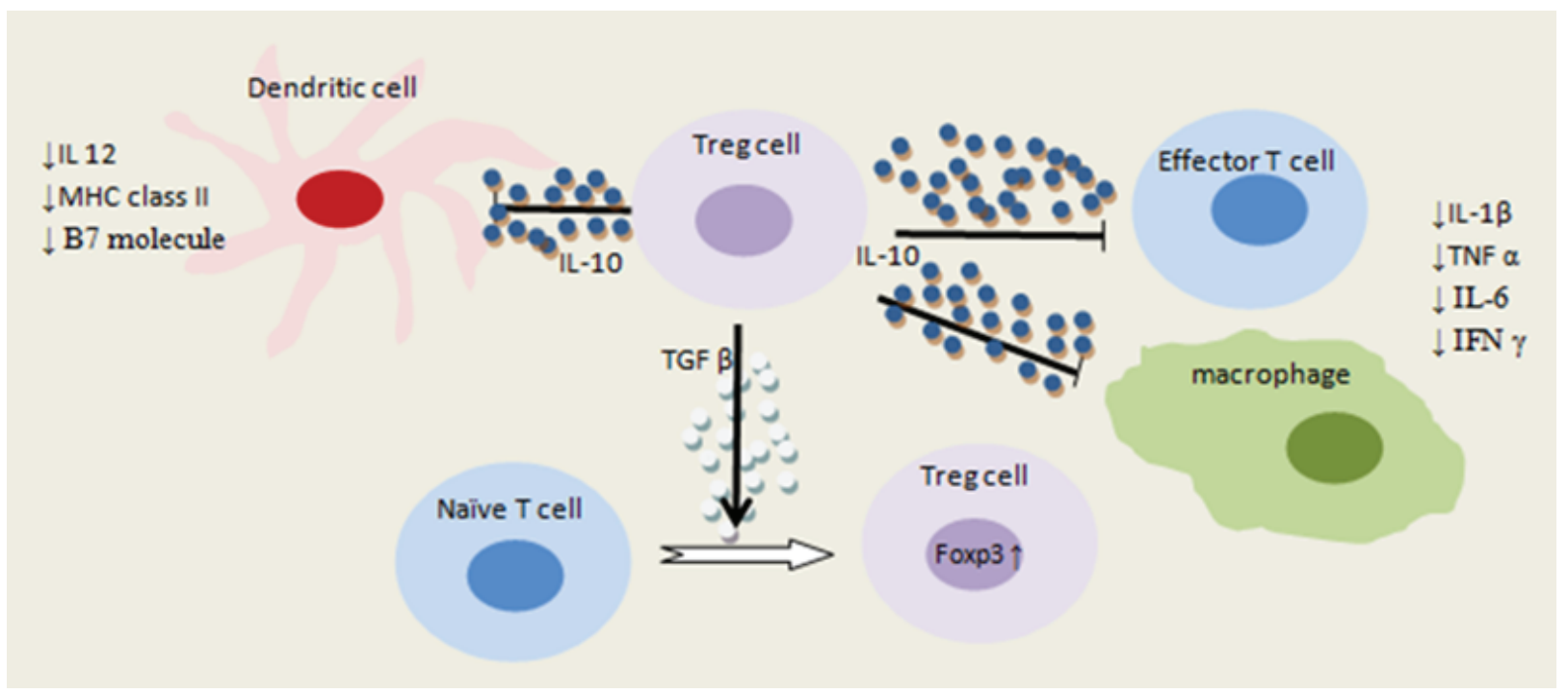

Figure 2. Mechanisms of non-contact inhibition by IL-10 and TGF- $\beta$ secreted by Treg cells.

adenosine monophosphate (AMP), which induces the inhibition of $\mathrm{T}$ cells proliferation, suppresses the production of IL-2, IFN- $\gamma$, and protein kinase A, and also activates transcription repressor inducible cAMP early repressor (ICER) and increases the production of pericellular adenosine that catalyzed by CD39 and CD73 in Treg cells. Adenosine would suppress the proliferation and cytokines production of effector $\mathrm{T}$ cells. . $^{21,24,27}$

Figure 3 shows mechanisms of Treg cell suppresses effector T cell and dendritic cell. Activated Treg cells could affect APCs function by suppressing the expression of B7 molecules and stimulating DCs to express indoleamine 2,3-dioxygenase (IDO). IDO would catalyze the conversion of tryptophan, an essential amino acids to kynurenine which is toxic to T cells. Both mechanisms depend on CTLA-4 in Treg cells which binds to B7 molecules in APCs. ${ }^{24,28} \mathrm{In}$ addition, Treg cells could also be activated by the small number of antigens presented by immature DCs that express low B7 molecules. ${ }^{27}$ Activated Treg cells could increase the expression of lymphocyte function-associated antigen 1 (LFA-1), and eventually, suppress the expression of B7 molecules in DCs to below the level needed for activation and expansion of effector T cells. ${ }^{24,27}$ Foxp $3^{+}$Treg cells have ability to suppress plasmacytoid DCs (pDCs) that express low level of B7 molecules. ${ }^{27}$

Another Treg suppression mechanism is the competition in consuming IL-2. ${ }^{28}$ As it is known that effector $\mathrm{T}$ cells, naïve, and effector T cells need IL-2 to proliferate and differentiate. Treg cells express CD25 which has high affinity to IL-2. Moreover, expression of CD25 allows Treg cells consume more IL-2 than effector T cells. Therefore, this competition induces apoptosis in the effector $\mathrm{T}$ cells that lack of IL-2. ${ }^{28}$ Apoptosis in the effector T cells is mediated by B-cell lymphoma 2 (Bcl-2) interacting mediator (BIM). ${ }^{21}$

\section{Regulatory T Cells in Type 2 DM}

Treg cells could inhibit the inflammatory response through the various pathways, such as increasing the secretion of antiinflammatory cytokines, modulating microenvironment, and changing the expression of cell receptors. ${ }^{28}$ The balance between Thelper (Th) 1 and Th17 cells as pro-inflammatory cells and Treg cells is very vital to maintain homeostasis and control tissue damages due to excessive inflammatory response. ${ }^{29}$

In peripheral blood of type $2 \mathrm{DM}$ patients, it was found that the proportion of $\mathrm{CD} 4^{+} \mathrm{T}$ cells were not different from the healthy controls, but the proportion of $\mathrm{CD} 4^{+} \mathrm{CD} 25^{+} \mathrm{Foxp} 3^{+}$ and $\mathrm{CD} 4{ }^{+} \mathrm{CD} 25^{+}$Treg cells decreased significantly. The proportion of $\mathrm{CD} 4^{+} \mathrm{CD} 25^{-} \mathrm{T}$ cells which would develop into other cell types did not show any differences. ${ }^{30}$

Treg cells circulate in peripheral blood including nTreg and iTreg cells. In type 2 DM patients, it was found that the percentage of nTreg cells did not decrease significantly, meanwhile the percentage of iTreg cells dropped dramatically, thus indicated that the decrease in the number and percentage of Treg cells in peripheral blood was caused by component of the peripheral immune system and it was not controlled by thymus. ${ }^{30}$ 


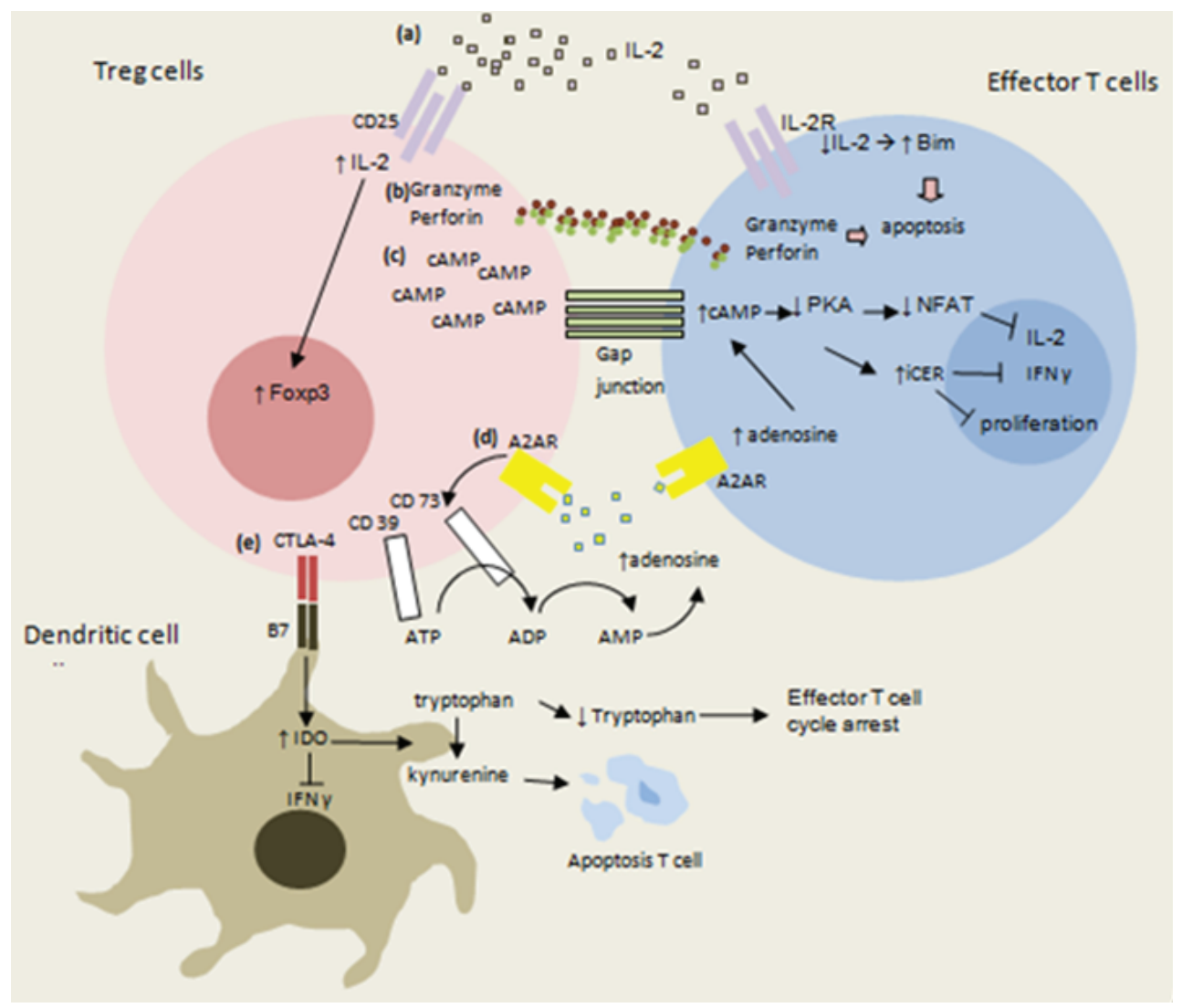

Figure 3. Mechanisms of Treg cell suppresses effector $\mathbf{T}$ cell and dendritic cell. (a): Treg cell expresses CD25 which has high affinity to IL-2, thus makes effector T cell is starvation and leads to cell death; (b): Granzyme and perforin secreted by Treg cell act on effector cell and cause apoptosis; (c): cAMP gets into effector cell trough gap junction and inhibits expression of proinflammatory cytokines and T cell proliferation; (d): CD73/CD39 on the surface of Treg cells converts ATP to adenine, which binds to A2A receptor on the effector T cells and inhibit the immune response; (e): CTLA-4 on the surface of Treg cells binds to B7 molecules on dendritic cell then promotes IDO secretion, IDO would inhibit interferon $\gamma$ and degrade tryptophan to kynurenine; kynurenine and depletion of tryptophan lead to effector cell apoptosis.

Treg cells in type 2 DM were found to be susceptible to apoptosis than Treg cells in healthy controls. The susceptibility of cells to apoptosis is controlled by the expression of Bcl-2 and Bax protein. The ratio of Bcl-2/ Bax in Treg cells in type 2 DM is significantly lower than normal. ${ }^{30}$ Therefore, this might be one of the other factors that cause fewer number of Treg cells in type 2 DM. In addition, dyslipidemia could be another factor that affects the number of Treg cells. ${ }^{30}$

CD39 is an ectoenzyme expressed in Treg cells. ${ }^{31}$ The function of CD39 is hydrolyzed adenosine triphosphate (ATP) and adenosine diphosphate (ADP) to AMP which is then converted by CD73 to adenosine metabolite that could suppress effector $\mathrm{T}$ cells. ${ }^{31,32} \mathrm{CD} 39$ is also related to the stability and suppressive function of Foxp $3^{+}$Treg cells. The expression of programmed death-ligand 1 (PD-L1), CD25, CTLA-4, and IL-10 are higher on the surface of CD39 $9^{\text {hi Treg }}$ cells compared to CD39 ${ }^{\text {low }}$ Treg cells..$^{32,33}$ A study reported

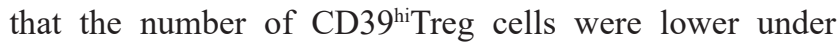
the chronic inflammatory conditions such as obesity and type $2 \mathrm{DM}^{32}$ Moreover, the percentages of $\mathrm{CD}^{3} 9^{+}$cells and $\mathrm{CD} 39^{+} \mathrm{CD} 19^{+}$cells were significantly associated with $\mathrm{HbA} 1 \mathrm{c}$ and fasting plasma glucose levels. ${ }^{34}$ Therefore, those might prove that the suppressive function of Treg cells is impaired in type $2 \mathrm{DM}$.

$\mathrm{T}$ lymphocytes could mediate mechanisms of immunopathology in type $2 \mathrm{DM}$ through various organs directly. The infiltration of T cells in the kidney is related to the development of diabetic nephropathy in type 2 DM..$^{35}$ This condition could be aggravated by the accumulation 
of macrophages and their proinflammatory cytokines, such as IFN- $\gamma$ and IL-1 $\beta$. A study conducted in diabetic nephropathy $\mathrm{db} / \mathrm{db}$ mice revealed Treg cells might improve nephropathy. ${ }^{35}$ Treg cells depletion through the administration of anti-CD25 would exacerbate nephropathy, renal dysfunction, and leukocytes infiltration of the kidney. Moreover, administration of Treg cells in diabetic nephropathy $\mathrm{db} / \mathrm{db}$ mice could alleviate renal function and dampen nephropathy. ${ }^{35}$

As discussed previously, both IL-10 and TGF- $\beta$ are potent anti-inflammatory cytokines produced by Treg cells. IL-10 could suppress proliferative activity in T cells, whereas TGF- $\beta$ maintains the expression of Foxp3 in Treg cells to improve immunosuppressive function. ${ }^{23}$ In type 2 DM, the serum level of IL-10 decreases, but the level of TGF- $\beta$ increases especially in the patient with diabetic complications such as retinopathy and nephropathy. ${ }^{36}$

\section{Association between Treg Cells and Th1/Th17 Cells in Type 2 DM}

During activation, naïve $\mathrm{CD} 4^{+} \mathrm{T}$ cells would differentiate to Th1, Th2, T Th17, or Treg cells and those depend on the presence of certain cytokines in the microenvironment.
Naïve T cells will differentiate to Th1 cell if IL-12 presents. Those cells will become Th2 cells if IL-4 presents. They will differentiate to Treg cells if there is TGF- $\beta$. The last, naïve T cells will become Th17 cells if TGF- $\beta$ and IL- 6 present. ${ }^{24}$

In a study, it was revealed that the number of Th1 and Th17 cells in the peripheral blood cells of type $2 \mathrm{DM}$ was higher. ${ }^{30}$ However, the ratio of Th17/Th1 cells in type $2 \mathrm{DM}$ was not different from healthy subjects. Th17 cells differentiation was correlated with the number of $\mathrm{CD}^{+} \mathrm{CD} 25^{+} \mathrm{Foxp}^{+}{ }^{+}$Treg cells in peripheral blood cells and the serum level of IL-6, IL-10 and TGF- $\beta$. Although IL-17 level did not differ between type $2 \mathrm{DM}$ and controls, the presence of IL-17 indicated that Th17 cells involved in the pathogenesis of type $2 \mathrm{DM}^{30} \mathrm{An}$ inflammatory condition in type 2 DM causes imbalance between Th1, Th17 and Treg cells population, as seen in Figure 4.

The decrease was seen in the ratio of $\mathrm{CD}^{+} \mathrm{CD} 25^{+}$ Treg/Th1 cells and $\mathrm{CD}^{+} \mathrm{CD} 25^{+}$Treg/Th17 cells. The similar result was also seen in the ratio $\mathrm{CD} 4^{+} \mathrm{CD} 25^{+} \mathrm{Foxp}^{+}$ Treg/Th1 cells and $\mathrm{CD} 4^{+} \mathrm{CD} 25^{+} \mathrm{Foxp}^{+}{ }^{+}$Treg/Th17 cells. ${ }^{31}$ Those ratios were not affected by the duration of DM and the serum level of $\mathrm{HbA} 1 \mathrm{c} .{ }^{31}$ This suggested that the duration and severity of hyperglycemia did not affect the balance between Treg, Th1 and Th17 cells.

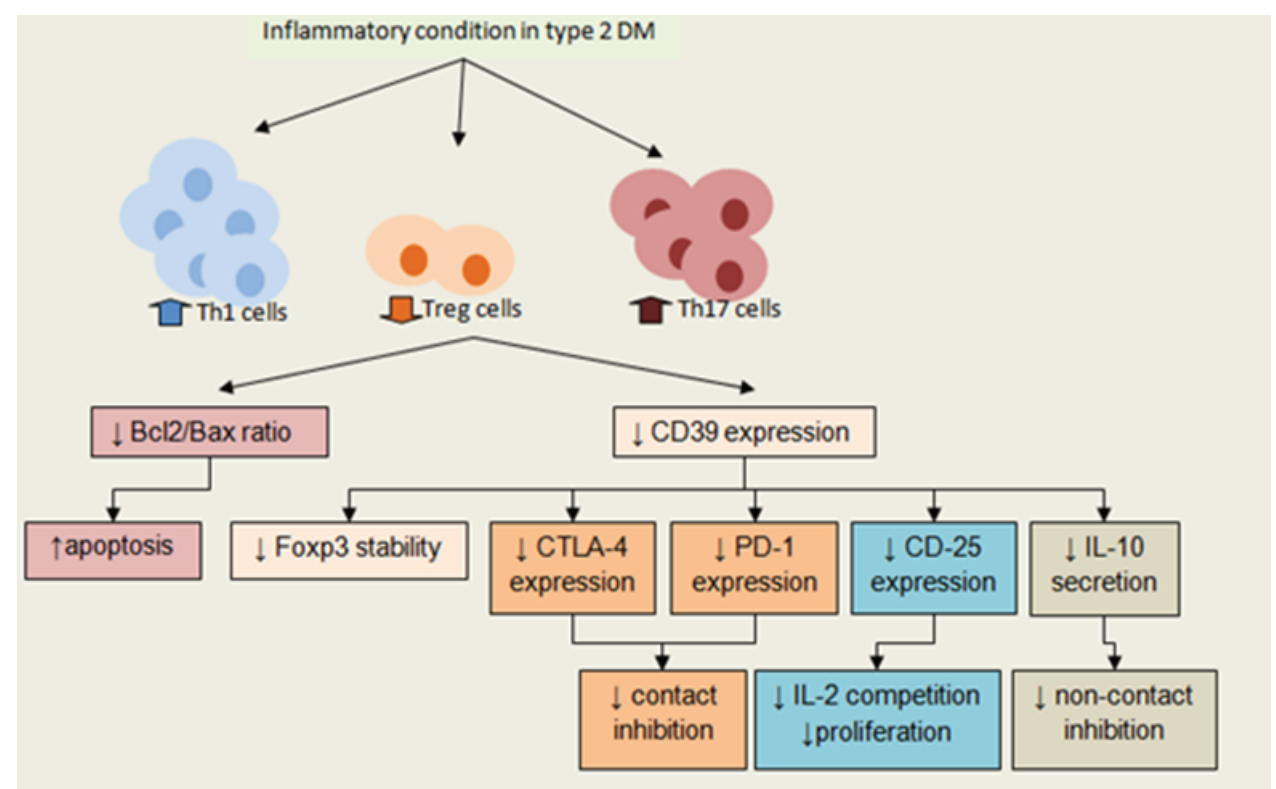

Figure 4. Inflammatory condition in type 2 DM causes imbalance between Th1, Th17 and Treg cells population. Futhermore, Treg cells undergo metabolic disruption, such as decreasing Bcl2/Bax ratio that leads to increase susceptibility to apoptosis, decreasing the expression of CD39 that disrupts the stability of Foxp3 gene, decreasing the expression of CTLA-4, PD-L1, CD25, and IL-10 secreation. Those would cause the suppression functions of Treg cells become impaired. 
Another study revealed that the imbalance in the population of $\mathrm{CD}^{+}$cells subset had occurred since the early stages of $\mathrm{DM}$ and far before the onset of complications..$^{30}$ In addition, the percentage of $\mathrm{CD} 4^{+} \mathrm{CD} 25^{+}$Treg cells in type $2 \mathrm{DM}$ with microvascular complication was lower compared to the healthy subjects and type $2 \mathrm{DM}$ with macrovascular complication meanwhile, the percentage of Th1 and Th17 cells increased in type $2 \mathrm{DM}$ patients with or without any complications. ${ }^{30}$

\section{Conclusion}

Inflammatory condition in type $2 \mathrm{DM}$ affects the proportion of $\mathrm{T}$ cell subsets, which characterized by increasing the number of Th1 and Th17 cells, while the number of Treg cells decreases. The number and function of Treg cells decline due to various things, including the percentage of iTreg cells decreases that indicates the defects in peripheral immune system, increased the ratio of Bcl-2/Bax in Treg cells indicates that Tregs cells are more susceptible to apoptosis, decreased the suppressive function of Treg cells as shown in mechanism of contact and non contact inhibition, and increased the level of pro-inflammatory cytokines that induce naïve $\mathrm{T}$ cell differentiation into Th1 and Th17 cells. This disturbance is likely happened since the early stage of DM or insulin resistance stage and far before the onset of complications.

\section{Acknowledgements}

Finally, we would like to thank all contributors of this article for their participation. We hope that this article will be helpful for the regulatory $\mathrm{T}$ cells research and the development of new therapeutic drugs for the modern treatment of diabetes and diabetes complication.

\section{References}

1. International Diabetes Federation. IDF Diabetes Atlas. 8 ed. Brussels: International Diabetes Federation; 2017.

2. Pusat Data dan Informasi Kementerian Kesehatan RI. Waspada Diabetes: Situasi dan Analisis Diabetes. Jakarta: Kementrian Kesehatan RI; 2014.

3. Kementerian Kesehatan Republik Indonesia. Menkes: Mari Kita Cegah Diabetes dengan Cerdik. Jakarta; Kementrian Kesehatan RI; 2016.

4. Mohiuddin SS. Low grade chronic inflammatory response in pathogenicity of diabetes mellitus. Curr Res Diabetes Obes J. 2018; 5(4): 1-6. doi: 10.19080/CRDOJ.2018.05.555666.

5. Chen L, Chen R, Wang H, Liang F. Mechanisms linking inflammation to insulin resistance. Int J Endocrino. 2015;2015:508409. doi: $10.1155 / 2015 / 508409$
6. Donath MY, Shoelson SE. Type 2 diabetes as an inflammatory disease. Nat Rev Immunol. 2011; 11(2): 98-107.

7. Osborn O, Olefsky JM. The cellular and signaling networks linking the immune system and metabolism in disease. Nat Med. 2012; 18(3): 363-74.

8. Herder C, Carstensen M, Owens DM. Anti-inflammatory cytokines and risk of type 2 diabetes. Diabetes Obes Metab. 2013; 15(3): 3950 .

9. Germain RN. Maintaining system homeostasis: the third law of Newtonian immunology. Nat Rev Immunol. 2012; 13(10): 902-6.

10. Kolb H, Mandrup-Poulsen T. An immune origin of type 2 diabetes? Diabetologia. 2005; 48(6): 1038-50.

11. Qiao YC, Shen J, He L, Hong X, Tian F, Pan YH, et al. Changes of regulatory $\mathrm{T}$ cells and of proinflammatory and immunosuppressive cytokines in patients with type 2 diabetes mellitus: A systematic review and meta-analysis. J Diabetes Res. 2016; 2016: 3694957. doi: $10.1155 / 2016 / 3694957$.

12. Yang TT, Song SJ, Xue HB, Shi DE, Liu M, Liu H. Regulatory T cells in the pathogenesis of type 2 diabetes mellitus retinopathy by miR155. Eur Rev Med Pharmacol Sci. 2015; 19(11): 2010-5.

13. Soelistijo SA, Novida H, Rudijanto A, Soewondo P, Suastika K, Manaf A, et al. Konsensus Pengelolaan dan Pencegahan Diabetes Melitus Tipe 2 di Indonesia 2015. Jakarta: PB PERKENI; 2015.

14. American Diabetes Association. Diagnosis and Classification of Diabetes Mellitus. Diabetes Care. 2010; 33(1): S62-9.

15. de Luca C, Olefsky JM. Inflammation and insulin resistance. FEBS Lett. 2008; 582(1): 97-105.

16. Wilcox G. Insulin and insulin resistance. Clin Biochem Rev. 2005; 26(2): 19-39.

17. Rehman K, Akash MSH. Mechanisms of inflammatory responses and development of insulin resistance: how are they interlinked? J Biomed Sci. 2016; 23: 87. doi: 10.1186/s12929-016-0303-y.

18. Wellen KE, Hotamisligil GS. Inflammation, stress, and diabetes. J Clin Invest. 2005; 115(5): 1111-9.

19. Dunham RM, Cervasi B, Brenchley JM, Albrecht H, Weintrob A, Sumpter B, et al. CD127 and CD25 expression defines CD4+ T cell subsets that are differentially depleted during HIV infection. J Immunol. 2008; 180(8): 5582-92.

20. Corthay A. How do regulatory T cells work? Scand J Immunol. 2009; 70(4): 326-36.

21. Abbas AK, Lichtman AH, Pillai S. Basic immunology: functions and disorders of the immune system. 5th ed. Missouri: Elsevier; 2016.

22. Venken K, Hellings N, Liblau R, Stinissen P. Disturbed regulatory $\mathrm{T}$ cell homeostasis in multiple sclerosis. Trends Mol Med. 2010; 16(2): 58-68.

23. Sokja DK, Huang YH, Fowell DJ. Mechanisms of regulatory T-cell suppression - a diverse arsenal for a moving target. Immunology. 2008; 124(1): 13-22.

24. Sakaguchi S, Yamaguchi T, Nomura T, Ono M. Regulatory T cells and immune tolerance. Cell. 2008; 133(5): 775-87.

25. Walter MR. The molecular basis of IL-10 function: from receptor structure to the onset of signaling. Curr Top Microbiol Immunol. 2014; 380: 191-212.

26. Conrad ML, Renz H, Blazer K. Immunological approaches for tolerance induction in allergy. Curr Top Microbiol Immunol. 2012; 352: 1-26.

27. Sakaguchi S, Wing K, Onishi Y, Prieto-Martin P, Yamaguchi T. Regulatory T cells: how do they suppress immune responses? IntImmunol. 2009; 21(10): 1105-11. 
28. Vignali DAA, Collison LW, Workman CJ. How regulatory T cells work. Nature Rev Immunol. 2008; 8(7): 523-32.

29. Xia C, Rao X, Zhong J. Role of T lymphocytes in type 2 diabetes and diabetes-associated inflammation. J Diabetes Res. 2017; 2017: 6494795. doi: 10.1155/2017/6494795.

30. Zeng C, Shi X, Zhang B, Liu He, Zhang L, Ding W, et al. The imbalance of Th17/Th1/Tregs in patients with type 2 diabetes: relationship with metabolic factors and complications. J Mol Med. 2012; 90(2): 175-86.

31. Borsellino G, Kleinewietfeld M, Di Mitri D, Sternjak A, Diamantini A, Giometto R, et al. Expression of ectonucleotidase CD39 by Foxp3+ Treg cells hydrolysis of extracellular ATP and immune suppression. Blood. 2007; 110(4): 1225-32.

32. Antonioli L, Pacher P, Vizi ES, Hasko G. CD39 and CD73 in immunity and inflammation. Trends Mol Med. 2013; 19(6): 355-67.
33. Gu J, Ni X, Pan X, Lu H, Lu Y, Zhao J. Human CD39hi regulatory $\mathrm{T}$ cells present stronger stability and function under inflammatory conditions. Cell Mol Immunol. 2017; 14(6): 521-8.

34. García-Hernández MH, Portales-Cervantes L, Cortez-Espinosa N, Vargas-Morales JM, Fritche-Salazar JF, Rivera-Lopez E, et al. Expression and function of $\mathrm{P} 2 \mathrm{X}(7)$ receptor and CD39/Entpd1 in patients with type 2 diabetes and their association with biochemical parameters. Cell Immunol. 2011; 269(2): 135-43.

35. Kornete M, Masin ES, Piccirillo CA. Immune regulation in T1D san T2D: prospective role of FoxP3+ Treg cells in disease pathogenesis and treatment. Frontiers. 2013; 4: 76. doi: 10.3389/ fendo.2013.00076

36. Qiao Y, Shen J, He L, Hong X, Tian F, Pan Y, et al. Changes of regulatory $\mathrm{T}$ cells and of proinflammatory and immunosuppressive cytokines in patients with type 2 diabetes mellitus: a systematic review and meta-analysis. J Diabetes Res. 2016: 1-19. 